\title{
TĂNG HUYẾT ÁP ÁO CHOÀNG TRẮNG VÀ TĂNG HUYẾT ÁP ẨN GIẤU Ở BỆNH NHÂN ĐTĐ TÍP 2: XUẤT ĐỘ VÀ YẾU TỐ LIÊN QUAN
} Nguyễ̂n Văn Lục ${ }^{i}$, Nguyễn Thị Bích Đà $\sigma^{2}$, Trần Kim Trang ${ }^{3}$ 1. BVĐK Binh Duong, NCS ĐH Y Duooc Tp HCM; 2. BV Tim Tâm Đức; 3. ĐH Y Dược Tp HCM

DOI: $10.47122 / v j d e .2020 .44 .1$

\section{TÓM TÁ́T}

Mở đầu: Tăng huyết áp (THA) là bệnh lý đi kèm thường gặp nhất trên người bệnh đái tháo đường (ĐTĐ). Các thể THA như THA áo choàng trắng và THA ẩn giấu có tỉ lệ khá cao đối với người bệnh ĐTĐ, đặc biệt là ĐTĐ típ 2. Muc tiêu: Xác định tỉ lệ và các yếu tố liên quan của THA áo choàng trắng và THA ẩn giấu trên người bệnh đái tháo đường típ 2. Đối tương và phương pháp nghiên cứu: Nghiên cứu mô tả cắt ngang trên 306 người bệnh tại phòng khám Nội Tiết ngoại trú, Bệnh viện Nhân Dân Gia Định TP.Hồ Chí Minh. Kết quả: $24,5 \%$ đối tượng có THA ẩn giấu, $30,1 \%$ có THA áo choàng trắng. Các yếu tố như độ tuổi, thời gian mắc ĐTĐ, tiền sử gia đình $\mathrm{THA}$, ĐTĐ, hút thuốc lá, uống rượu bia, ăn mặn và tập thể dục có mối liên quan chung với các thể THA. Kết luận: Kết quả nghiên cứu nhắc lại việc ứng dụng đo huyết áp liên tục 24 giờ trong xác định các thể THA, góp phần phòng ngừa các biến cố bất lợi do THA gây ra trên người bệnh ĐTĐ típ 2.

Tù khóa: THA áo choàng trắng, THA ẩn giấu, ĐTĐ típ 2, yếu tố nguy co

\section{ABSTRACT \\ White-coat hypertension and masked \\ hypertension in diabetic type 2 patients: \\ Prevalence and their related factors \\ Nguyen Van Luc ${ }^{1}$, Nguyen Thi Bich Dao ${ }^{2}$, Tran Kim Trang ${ }^{3}$ \\ 1. Binh Duong General hospital, student of PhD in University of Medicine and Pharmacy at Ho Chi Minh city; 2. Tam Duc Heart Hospital; 3. University of Medicine and Pharmacy at Ho Chi Minh city}

Introduction: Hypertension is the most common comorbidity of diabetes. White-coat and masked hypertension are high prevalence hypertension phenotypes, especially in type 2 diabetic patients. Objectives: To evaluate the prevalence and related factors of white-coat and masked hypertension in type 2 diabetic patients. Method: A cross-sectional study was conducted in 306 diabetic type 2 patients in Nhan Dan Gia Dinh hospital - Ho Chi Minh city. Results: The prevalence of white-coat and masked hypertension were $30.1 \%$ and $24.5 \%$, respectively. Age, family history of hypertension, diabetes, smoking, drinking, salt consuming, and physical activites were associated with hypertension phenotypes. Conclusion: Data remind us of application ambulatory blood pressure monitoring to identify hypertension phenotypes for prevention adverse events in type 2 diabeticsubjects.

Keyword: White-coat hypertension, masked hypertension, diabetes type 2, related factors

Chịu trách nhiệm chính: Nguyễn Văn Lực

Ngày nhận bài: 15/8/2020

Ngày phản biện khoa học: 11/9/2020

Ngày duyệt bài: 26/1/2021

Email: nguyenvanlucphoto@gmail.com

Điện thoại: 0909762699

\section{1. ĐẶT VẤN ĐỀ}

Tăng huyết áp (THA) và đái tháo đường (ĐTĐ) là hai bệnh lý mạn tính đang gia tăng với tốc độ nhanh chóng trên toàn cầu. Sự tác động cộng hợp giữa THA và ĐTĐ gây nhiều hệ quả nghiêm trọng đến hệ thống tim mạch. Bệnh nhân ĐTĐ kèm THA tăng nguy cơ tim mạch gấp 2 - 4 lần so với người ĐTĐ không THA. Nghiên cứu Framingham cũng đã chứng minh rằng THA kết hợp ĐTĐ làm tăng 30\% nguy cơ tử vong chung và $25 \%$ các biến cố tim mạch ${ }^{(3)}$. Vì vậy việc chẩn đoán và điều trị THA trên bệnh nhân ĐTĐ cần phải nghiêm ngặt hơn. 
Việc đánh giá THA dựa trên huyết áp khi thăm khám lâm sàng thông thường được ghi nhận là chưa phản ánh chính xác được giá trị huyết áp thật sự của hơn $50 \%$ các trường hợp được đo ${ }^{(8)}$. Theo ghi nhận, huyết áp của một người có xu hướng dao động theo chu kỳ ngày và đêm, tăng giảm tùy thuộc vào hoàn cảnh hiện tại như nghỉ ngơi, lao động thể lực hay trí óc, chịu ảnh hưởng bởi yếu tố tâm lý, môi trường. Do đó, việc chẩn đoán và điều trị THA còn nhiều vấn đề cần làm rõ. Việc áp dụng kỹ thuật đo huyết áp liên tục 24 giờ giúp giải quyết được sự thay đổi của huyết áp. Với kỹ thuật này, nhà lâm sàng có thể chẩn đoán tăng huyết áp áo choàng trắng, THA thật sự, THA ẩn giấu hay không THA. Trong các hướng dẫn điều trị THA Anh Quốc, Canada, Châu Ầu... đã đưa huyết áp liên tục 24 giờ vào chẩn đoán các thể THA này ${ }^{(5)(7)}$.

Các nghiên cứu gần đây cho thấy rằng cả THA áo choàng trắng lẫn THA ẩn giấu đều có liên quan với sự gia tăng các biến cố về tim mạch, đặc biệt ở bệnh nhân ĐTĐ ${ }^{(10)}$. Tuy nhiên, hầu hết các thể THA này đều ít được chú ý khi thăm khám thông thường. Việc này vô tình làm diễn tiến THA gây hại đến cơ thể nhưng không được đánh giá và điều trị chính xác. Các nghiên cứu về ứng dụng huyết áp liên tục 24 giờ để đánh giá các thể THA trên thế giới đã được ghi nhận, song tại Việt Nam còn hạn chế. Việc ứng dụng hiện nay tại Việt Nam chủ yếu tại các trung tâm tim mạch lớn, do đó, tỉ lệ THA áo choàng trắng và THA ẩn giấu trên dân số Việt Nam chưa được đánh giá một cách đầy đủ. Nghiên cứu được tiến hành nhằm đánh giá tỉ lệ THA áo choàng trắng và THA ẩn giấu, xác định các yếu tố liên quan để từ đó có cái nhìn tổng quát và là cơ sở điều trị cho người bệnh ĐTĐ típ 2.

\section{2. ĐỐI TƯợNG VÀ PHƯƠNG PHÁP NGHIÊN CÚU}

2.1. Đối tượng nghiên cứu: Tất cả người bệnh đang điều trị hay mới chẩn đoán ĐTĐ típ 2 theo tiêu chuẩn chẩn đoán của Hiệp hội ĐTĐ Hoa Kì năm 2017, trên 18 tuổi, không đang uống thuốc hạ áp được chọn ngẫu nhiên hệ thống dựa trên ước lượng số lượt bệnh đến khám trung bình mỗi ngày. Người bệnh bị loại trừ khỏi nghiên cứu khi ghi nhận ĐTĐ típ 1, ĐTĐ thai kỳ, bệnh nhân mắc các bệnh lý cấp tính như: có sốt (trên $38^{\circ} \mathrm{C}$ ), nhiễm trùng đường tiểu, đang điều trị với cimetidine; có hoạt động thể lực gắng sức trong vòng 24 giờ; đang hành kinh; nước tiểu dưới $500 \mathrm{ml} / 24$ giờ; có tiền căn đột quy, suy tim phân suất tống máu giảm (EF dưới $50 \%$ ), suy thận mạn nồng độ creatinine huyết thanh trên $2 \mathrm{mg} / \mathrm{dl}$, tăng huyết áp đang điều trị.

\subsection{Phương pháp nghiên cứu}

\section{Đánh giá huyết áp liên tục 24 giò̀}

Người bệnh được đo huyết áp liên tục 24 giờ bằng máy MICROLIFE 24H WATCHBP O3, được kiểm nghiệm qua ba tiêu chuẩn quốc tế: Hiệp hội Tăng huyết áp Anh, Châu Âu và Hiệp hội Dụng cụ Y khoa. Máy đo theo phương pháp dao động mạch, nhỏ, băng từ ghi lại kêt quả trong 24 giờ. Màn hình hiển thị huyết áp tâm thu, huyết áp tâm trương, tần số tim. Máy đo tự động bơm căng túi hơi và xả hơi từ từ 2$3 \mathrm{mmHg}$. Băng quấn: $25 \times 35 \mathrm{~cm}$. Phần mềm AccuWinPro v3: thời gian theo dõi huyết áp 24 giờ, thời gian ngày từ 6 giờ đến 22 giờ (mỗi 30 phút đo 1 lần) và thời gian đêm từ 22 giờ đến 6 giờ (60 phút đo 1 lần).

Dựa trên các giá trị huyết áp, nghiên cứu chia làm 4 nhóm:

- HA được xem là bình thường thật sự khi: HA tại phòng khám dưới 140/90mmH $\mathrm{g}$ và HALT 24 giờ có: HA ban ngày dưới $135 / 85 \mathrm{mmHg}$ và $\mathrm{HA} 24$ giờ dưới $130 / 80 \mathrm{mmHg}$.

- THA thật sự được xác định khi:

+ HA tại phòng khám $\geq 140 / 90 \mathrm{mmHg}$ và

+ HALT 24 giờ có :

- HA ban ngày $\geq 135 / 85 \mathrm{mmHg}$ và/hoặc

- HA 24 giờ $\geq 130 / 80$ mmHg

- THA ẩn giấu

+ Huyết áp đo ở phòng khám dưới $140 / 90 \mathrm{mmHg}$ và

+ HALT 24 giờ:

- HA ban ngày $\geq 135 / 85$ mmHg và hoặc

- HA 24 giờ $\geq 130 / 80 \mathrm{mmHg}$

- THA áo choàng trắng: được xác định trên NB không được điều trị THA khi HA đo tại phòng khám $\geq 140 / 90 \mathrm{mmHg}$ và HALT 24 giờ 
có HA ban ngày dưới 135/85 mmHg và HA 24 giờ dưới 130/80 mmHg

Phuơng pháp thu thập dĩ liệu: lấy mẫu ngẫu nhiên hệ thống, người bệnh thỏa mãn các tiêu chí chọn mẫu và tiêu chí loại trừ. Mẫu nghiên cứu được gắn huyết áp liên tục 24 giờ, nhân viên y tế hướng dẫn người bệnh tuân thủ và ghi nhận các thông tin liên quan nghiên cứu.

\section{Phương pháp xử lý dĩ liệu}

Nhập liệu trên Microsoft Excel, sử dụng phần mềm Stata 14.0 để phân tích. Phép kiểm $\chi 2$ đánh giá mối liên quan giữa các thể THA với các biến số định tính như giới tính, hút thuốc lá, uống rượu, tiền sử gia đình,... Phép kiểm ANOVA, post-hoc Tukey's test đánh giá mối liên quan giữa các thể THA với biến số định lượng; phép kiểm Kruskal-Wallis, posthoc Dunn's test được sử dụng khi không thỏa điều kiện đánh giá bởi ANOVA. Giá trị $\mathrm{p}<0,05$ được đánh giá là có ý nghĩa về mặt thống kê.

\section{KẾT QUẢ NGHIÊN CÚU}

Nghiên cứu ghi nhận dữ liệu trên 306 người bệnh đến khám ngoại trú tại phòng khám Nội Tiết, Bệnh viện Nhân Dân Gia Định TP.Hồ Chí Minh.

\section{1. Đặc điểm mẫu nghiên cứu}

Tỉ lệ giới tính trong nghiên cứu tương đối đồng đều (48,5\% ở nam giới và 51,5\% ở nữ giới). Độ tuổi trung bình là $53,8 \pm 9,8$ tuổi. Có $51,9 \%$ mẫu nghiên cứu có tiền sử gia đình bị THA, tiền sử ĐTĐ ghi nhận ở $60,5 \%$ người bệnh. Tỉ lệ hút thuốc lá là $23,6 \%$, uống rượu bia là $8,1 \%$, ăn mặn là $47,8 \%$ và tập thể dục là $45,5 \%$. Thời gian mắc bệnh đái tháo đường trung bình là $5,27 \pm 4,54$ năm, cao nhất 30 năm và thấp nhất là 1 năm

\subsection{Phân loại tăng huyết áp}

Bảng 1. Các thể THA trong nghiên cứu $(n=306)$

\begin{tabular}{|l|c|c|}
\hline \multicolumn{1}{|c|}{ Các thể THA } & Tà̀n số & Tỉ lệ (\%) \\
\hline Không THA & 139 & 45,4 \\
\hline THA áo choàng trắng & 92 & 30,1 \\
\hline THA ẩn giấu & 75 & 24,5 \\
\hline
\end{tabular}

3.3. Các yếu tố liên quan đến tăng huyết áp

Bảng 2. Đặc điểm nhân trắc của mẫu nghiên cứu $(\mathrm{n}=306)$

\begin{tabular}{|c|c|c|c|c|c|c|c|}
\hline & \multicolumn{3}{|c|}{ Phân loại tăng huyết áp } & \multirow[b]{2}{*}{$\mathbf{p}_{1}$} & \multirow[b]{2}{*}{$\mathbf{p}_{2}$} & \multirow[b]{2}{*}{$\mathbf{p}_{3}$} & \multirow[b]{2}{*}{$\mathbf{p}_{4}$} \\
\hline & $\begin{array}{c}\text { Không } \\
\text { THA } \\
(n=139)\end{array}$ & $\begin{array}{c}\text { THA } \\
\text { áo choàng } \\
\text { trắng } \\
(\mathrm{n}=92)\end{array}$ & $\begin{array}{c}\text { THA } \\
\text { ẩn giấu } \\
(n=75)\end{array}$ & & & & \\
\hline Tuổi & $52,2 \pm 9,9$ & $51,7 \pm 8,6$ & $59,3 \pm 9,1$ & $<0,001$ & 0,910 & $<0,001$ & $<0,001$ \\
\hline $\begin{array}{l}\text { BMI } \\
\left(\mathrm{kg} / \mathrm{m}^{2}\right)\end{array}$ & $23,2 \pm 2,7$ & $23,2 \pm 2,7$ & $23,3 \pm 3,2$ & 0,923 & 1,000 & 0,927 & 0,938 \\
\hline
\end{tabular}

Giới tính

\begin{tabular}{|l|l|l|l|l|l|l|l|}
\cline { 1 - 4 } Nam & $73(52,5)$ & $26(28,3)$ & $46(61,3)$ & \multirow{2}{*}{$<0,001$} & $<0,001$ & 0,216 & $<0,001$ \\
\hline Nữ & $66(47,5)$ & $66(71,7)$ & $29(38,7)$ & & & & \\
\hline
\end{tabular}

$\mathrm{p}_{1}$ : đánh giá khác biệt chung, $\mathrm{p}_{2}$ : đánh giá khác biệt giữa THA áo choàng trắng với không THA, $\mathrm{p}_{3}$ : đánh giá khác biệt giữa THA ẩn giấu với không THA, $\mathrm{p}_{4}$ : đánh giá khác biệt giữa THA áo choàng trắng và THA ân giấu

Có sự khác biệt về độ tuổi trung bình và giới tính giữa các thể THA, cụ thể tuổi trung bình của nhóm THA ẩn giấu cao hơn so với hai nhóm còn lại và sự khác biệt có ý nghĩa thống kê. Nam giới có tỉ lệ THA ẩn giấu cao hơn so với nữ giới và so với các nhóm THA còn lại. 
Bảng 3. Đặc điểm các yếu tố nguy cơ của các thể tăng huyết áp (n=306)

\begin{tabular}{|c|c|c|c|c|c|c|c|}
\hline & \multicolumn{3}{|c|}{ Phân loại tăng huyết áp } & \multirow[b]{2}{*}{$\mathbf{p}_{1}$} & \multirow[b]{2}{*}{$\mathbf{p}_{2}$} & \multirow[b]{2}{*}{$\mathbf{p}_{3}$} & \multirow[b]{2}{*}{$\mathbf{p}_{4}$} \\
\hline & $\begin{array}{c}\text { Không } \\
\text { THA } \\
(n=139)\end{array}$ & $\begin{array}{c}\text { THA } \\
\text { áo choàng } \\
\text { trắng } \\
(\mathrm{n}=92)\end{array}$ & $\begin{array}{c}\text { THA } \\
\text { ẩn giấu } \\
(n=75)\end{array}$ & & & & \\
\hline \multicolumn{8}{|c|}{ Thời gian mắc đái tháo đường } \\
\hline$\geq 5$ năm & $48(34,5)$ & $48(52,1)$ & $44(58,7)$ & \multirow{2}{*}{0,001} & \multirow{2}{*}{0,008} & \multirow{2}{*}{0,001} & \multirow{2}{*}{0,401} \\
\hline < 5 năm & $91(65,4)$ & $44(47,8)$ & $31(41,3)$ & & & & \\
\hline \multicolumn{8}{|c|}{ Tiền sử gia đình THA } \\
\hline Có & $46(33,1)$ & $55(59,8)$ & $55(73,3)$ & \multirow{2}{*}{$<0,001$} & \multirow{2}{*}{$<0,001$} & \multirow{2}{*}{$<0,001$} & \multirow{2}{*}{0,066} \\
\hline Không & $93(66,9)$ & $37(40,2)$ & $20(26,7)$ & & & & \\
\hline \multicolumn{8}{|c|}{ Tiền sử gia đình ĐTD } \\
\hline Có & $69(49,6)$ & $71(77,2)$ & $45(60,0)$ & \multirow{2}{*}{$<0,001$} & \multirow{2}{*}{$<0,001$} & \multirow{2}{*}{0,147} & \multirow{2}{*}{0,017} \\
\hline Không & $70(50,4)$ & $21(22,8)$ & $30(40,0)$ & & & & \\
\hline \multicolumn{8}{|c|}{ Hút thuốc lá } \\
\hline Có & $33(23,7)$ & $7(7,6)$ & $30(40,0)$ & \multirow{2}{*}{$<0,001$} & \multirow{2}{*}{0,002} & \multirow{2}{*}{0,013} & $<0,00$ \\
\hline Không & $106(76,3)$ & $85(92,4)$ & $45(60,0)$ & & & & 1 \\
\hline \multicolumn{8}{|c|}{ Uống rượu bia } \\
\hline Có & $13(9,4)$ & $2(2,2)$ & $9(12,0)$ & \multirow{2}{*}{0,042} & \multirow{2}{*}{0,030} & \multirow{2}{*}{0,543} & \multirow{2}{*}{0,011} \\
\hline Không & $126(90,6)$ & $90(97,8)$ & $66(88,0)$ & & & & \\
\hline \multicolumn{8}{|l|}{ Ăn mặn } \\
\hline Có & $52(37,4)$ & $47(51,1)$ & $46(61,3)$ & \multirow{2}{*}{0,003} & \multirow{2}{*}{0,040} & \multirow{2}{*}{0,001} & \\
\hline Không & $87(62,6)$ & $45(48,9)$ & $29(38,7)$ & & & & 0,185 \\
\hline Tập thể & & & & & & & \\
\hline Có & $74(53,2)$ & $30(32,6)$ & $37(49,3)$ & $0 \cap 007$ & 0007 & 0586 & 0028 \\
\hline Không & $65(46,8)$ & $62(67,4)$ & $38(50,7)$ & 0,001 & 0,002 & 0,500 & $0,0<0$ \\
\hline
\end{tabular}

$\mathrm{p}_{1}$ : đánh giá khác biệt chung, $\mathrm{p}_{2}$ : đánh giá khác biệt giữa THA áo choàng trắng với không THA, $\mathrm{p}_{3}$ : đánh giá khác biệt giữa THA ẩn giấu với không THA, $\mathrm{p}_{4}$ : đánh giá khác biệt giữa THA áo choàng trắng và THA ẩn giấu

Các yếu tố như thời gian mắc bệnh ĐTĐ típ 2, tiền sử gia đình THA, ĐTĐ, hút thuốc lá, uống rượu bia, ăn mặn và tập thể dục có mối liên quan chung với các thể THA.

Bảng 4. Đặc điểm sinh hóa của các thể huyết áp $(n=306)$

\begin{tabular}{|c|c|c|c|c|c|c|c|}
\hline & \multicolumn{3}{|c|}{ Phân loại tăng huyết áp } & \multirow[b]{2}{*}{$\mathbf{p}_{1}$} & \multirow[b]{2}{*}{$\mathbf{p}_{2}$} & \multirow[b]{2}{*}{$\mathbf{p}_{3}$} & \multirow[b]{2}{*}{$\mathbf{p}_{4}$} \\
\hline & $\begin{array}{c}\text { Không } \\
\text { THA } \\
(n=139)\end{array}$ & $\begin{array}{c}\text { THA } \\
\text { áo choàng } \\
\text { trắng } \\
(n=92)\end{array}$ & $\begin{array}{c}\text { THA } \\
\text { ẩn giấu } \\
(n=75)\end{array}$ & & & & \\
\hline $\begin{array}{l}\text { Đường huyết } \\
\text { đói }(\mathrm{mmol} / \mathrm{L})\end{array}$ & $8,30 \pm 2,71$ & $\begin{array}{c}8,46 \pm \\
2,65\end{array}$ & $\begin{array}{c}8,52 \pm \\
2,68\end{array}$ & 0,819 & 0,888 & 0,836 & 0,991 \\
\hline $\begin{array}{l}\text { HbA1c >7\% } \\
(\%)\end{array}$ & $64(46,0)$ & $53(57,6)$ & $44(58,7)$ & 0,109 & 0,085 & 0,078 & 0,890 \\
\hline $\begin{array}{l}\text { Rối loạn lipid } \\
\text { máu }(\%)\end{array}$ & $115(82,7)$ & $76(82,6)$ & $61(81,3)$ & 0,965 & 0,980 & 0,798 & 0,831 \\
\hline
\end{tabular}

$\mathrm{p}_{1}$ : đánh giá khác biệt chung, $\mathrm{p}_{2}$ : đánh giá khác biệt giữa THA áo choàng trắng với không THA, $\mathrm{p}_{3}$ : đánh giá khác biệt giữa THA ẩn giấu với không THA, $\mathrm{p}_{4}$ : đánh giá khác biệt giữa THA áo 
choàng trắng và THA ẩn giấu. Nghiên cứu không có sự khác biệt về các thể HA theo các đặc điểm bất thường sinh hóa.

\section{BÀN LUẬ. \\ 4.1. Các thể THA trên người bệnh ĐTĐ típ 2}

Tỉ lệ mẫu nghiên cứu có THA áo choàng trắng là $30,1 \%$, cao hơn so với kết quả của Liana FF (2015) với 17,1,7\% ${ }^{(6)}$, nhưng lại thấp hơn nghiên cứu của Gorostidi $M$ (2011) với $37,5 \%{ }^{(4)}$. Đối với THA ẩn giấu, nghiên cứu của chúng tôi ghi nhận $24,5 \%$ mẫu nghiên cứu có thể THA này, tương đối gần với kết quả của Võ Thị Hà Hoa (2013) với 21,4\%(2) và Tomiyama M (2006) với 22,0\% $\%^{(9)}$, thấp hơn so với Nguyễn Trần Tuyết Trinh (2013) là $57,8 \%{ }^{(1)}$. Sự khác biệt về các kết quả nghiên cứu có thể do việc chọn đối tượng nghiên cứu và giới hạn cài đặt mức huyết áp cho máy đo huyêt áp liên tục 24 giờ. Nhìn chung, THA ẩn giấu và THA áo choàng trắng chiếm tỉ lệ tương đối cao, cần được quan tâm chú ý trong quá trình điều trị, đặc biệt là trên các đối tượng có các yếu tố nguy cơ, cụ thể là người bệnh ĐTĐ típ 2 . Ngoài ra, các nghiên cứu trên cũng đã chứng minh THA ẩn giấu và THA áo choàng trắng thường không được đánh giá đúng mức, từ đó gây nhiều tồn thương cho cơ quan đích ${ }^{(1)(2)}$. Điều này cho thấy, việc ứng dụng rộng rãi đo huyết áp liên tục 24 giờ là cần thiết cho việc phát hiện sớm các thể THA, từ đó, có liệu pháp điều trị phù hợp, giảm tác động bất lợi đến các cơ quan đích.

\subsection{Các yếu tố nguy cơ của THA áo choàng trắng và THA ẩn giấu}

Các yếu tố nguy cơ của bệnh lý THA đã được xác định rõ ràng thông qua các nghiên cứu trong và ngoài nước ${ }^{(3)(5)}$. Đặc biệt đối với người bệnh ĐTĐ, nguy cơ THA tăng gấp 2 lần và các tác động bất lợi cũng cao hơn so với người bệnh không ĐTĐ ${ }^{(3)}$. Đối với nhóm người bệnh ĐTĐ típ 2, trọng lượng cơ thể, tuổi, giới, các tiền căn y khoa bản thân gia đình và các yếu tố về lối sống không lành mạnh góp phần đẩy mạnh tình trạng THA ở nhóm này.

Độ tuổi và giới tính là hai yếu tố không thay đổi được luôn chú trọng đánh giá trong $\mathrm{THA}^{(7)}$. Cụ thể, nam giới có tỉ lệ THA cao hơn so với nữ giới và độ tuổi càng cao thì tỉ lệ THA càng tăng. Trong nghiên cứu đang tiến hành, độ tuổi và giới tính có sự ảnh hưởng rõ rệt đến các thể THA: nhóm THA ẩn giấu có tuổi trung bình cao hơn so với nhóm không THA, và nhóm THA áo choàng trắng. Bên cạnh đó, nam giới có tình trạng THA ẩn giấu cao hơn so với nữ giới, trong khi đó THA áo choàng trắng lại thường gặp ở nữ giới nhiều hơn. Xét về bản chất, THA áo choàng trắng chưa phải là bệnh THA thật sự, trong khi đó THA ẩn giấu được xem là bệnh lý nhưng chưa được phát hiện ra qua thăm khám thông thường. Điều này càng thể hiện rõ mối liên quan chặt chẽ giữa độ tuổi, giới tính và sự phát triển của bệnh lý THA. Việc sàng lọc THA, chủ yếu về THA ẩn giấu trên người cao tuổi và người bệnh ĐTĐ típ 2 cần được lưu ý.

ĐTĐ vừa là nguyên nhân vừa là hậu quả trực tiếp của THA. Thời gian mắc đái tháo đường cũng là một trong những yếu tố được chú trọng đánh giá trên người bệnh có THA. Thời gian mắc bệnh ĐTĐ càng lâu thì khả năng mắc THA càng tăng ${ }^{(2)(7)}$. Kết quả nghiên cứu cũng cho kết quả tương tự khi tỉ lệ nhóm THA áo choàng trắng và THA ẩn giấu ở nhóm những người mắc ĐTĐ típ 2 trên 5 năm cao hơn so với nhóm dưới 5 năm. Đối với THA áo choàng trắng, xảy ra chủ yếu là do tâm lý của người bệnh lo lắng về tình trạng sức khỏe của bản thân, thường gặp ở những người mới mắc bệnh. Đối với THA ẩn giấu, đây là tình trạng bệnh lý thật nhưng khó đánh giá trên lâm sàng, thường gặp ở người bệnh lớn tuổi và có mắc kèm ĐTĐ.

Tiền sử gia đình về THA và ĐTĐ được đánh giá là các yếu tố có liên quan đến tình trạng THA hiện tại của đối tượng nghiên cứu. Về cơ chế tác động trực tiếp của vấn đề này chưa được đánh giá một cách chính xác. Các nghiên cứu chuyên sâu về di truyền cần được tiến hành để xác định mối liên quan thật sự giữa tiền căn gia đình THA, ĐTĐ và tình trạng bệnh lý của thế hệ tiếp theo.

Yếu tố về hành vi lối sống không lành mạnh 
như ăn mặn, uống rượu bia, hút thuốc lá, ít vận động thể lực là các yếu tố có tác động trực tiếp đến tình trạng THA, ĐTĐ ${ }^{(8)(10)}$. Sự tác động của các yếu tố này vừa ảnh hưởng trực tiếp, vừa thúc đẩy và tác động lẫn nhau lên tình trạng THA, ĐTĐ, làm cho vấn đề này trở nên trầm trọng hơn. Nghiên cứu đang tiến hành cũng ghi nhận kết quả tương tự so với các nghiên cứu trước đó về các yếu tố hành vi lối sống không lành mạnh và tác động thúc đẩy của các yếu tố này lên THA trên người bệnh ĐTĐ típ 2. Việc tư vấn, truyền thông giáo dục sức khỏe, hỗ trợ thay đổi hành vi, chuyển đổi từ các hành vi có hại thành các hành vi không có hại hoặc có lợi là cần thiết. Điều này một phần hỗ trợ phòng ngừa và làm giảm thiểu các tác động bất lợi của các hành vi không lành mạnh lên sức khỏe mỗi cá nhân.

Nghiên cứu ghi nhận không có sự khác biệt về đường huyết đói, các chỉ số về rối loạn mỡ máu giữa các nhóm THA. Điều này là do mẫu nghiên cứu của chúng tôi hoàn toàn là người bệnh ĐTĐ típ 2, sự hiện diện của các yếu tố này hầu như là ở tất cả các đối tượng nghiên cứu.

Đối với THA áo choàng trắng, đây không phải là bệnh tăng huyết áp thật sự, tuy nhiên đây cũng không phải là một hiện tượng hoàn toàn lành tính. Các nghiên cứu ghi nhận người bệnh THA áo choàng trắng có nguy cơ tim mạch thấp hơn bệnh nhân THA thật sự nhưng cao hơn những người có huyết áp hoàn toàn bình thường ${ }^{(3)}$. Thông thường, bác sĩ điều trị lẫn người bệnh thường ít để ý đến THA áo choàng trắng vì cho rằng đây là hiện tượng xảy ra do tâm lý người bệnh. Mặc dù vậy, việc đánh giá thể THA này cũng cần thiết cho các phương án điều trị, phòng ngừa THA trên đối tượng người bệnh ĐTĐ típ 2.

So với THA áo choàng trắng, THA ẩn giấu thường được chú ý đánh giá nhiều hơn vì tác động của thể THA này là tương đương với THA thật sự nhưng lại khó phát hiện thông qua thăm khám lâm sàng thông thường. Các yếu tố nguy cơ của THA ẩn giấu không nằm ngoài các yếu tố nguy cơ của bệnh lý THA nói chung như thời gian mắc bệnh đái tháo đường, tăng cholesterol tăng triglycerid có liên quan đến
THA ẩn giấu ${ }^{(2)}$. Trong nghiên cứu của chúng tôi các yếu tố này chưa ghi nhận có mối liên quan có ý nghĩa thống kê. Sự khác biệt về kết quả nghiên cứu của chúng tôi là do khác biệt về đối tượng nghiên cứu. Nghiên cứu của tôi thực hiện trên đối tượng là người bệnh ĐTĐ típ 2, còn nghiên cứu của Võ Thị Hà Hoa lại thực hiện trên đối tượng là người bệnh THA. Mặc dù vậy, việc kiểm soát tốt các yếu tố kể trên là cần thiết, vì đây là các yếu tố không chỉ ảnh hưởng đến THA, ĐTĐ mà còn nhiều các bệnh lý khác.

\section{KẾT LUẬN}

Khi đánh giá THA trên người bệnh ĐTĐ típ 2, cần chú ý đánh giá về các thể THA áo choàng trắng và THA ẩn giấu vì các thể THA này khó phát hiện, phân biệt trên thăm khám lâm sàng thông thường. Việc phân định rõ các thể THA giúp nhà lâm sàng có phương hướng điều trị và phòng ngừa thích hợp, giảm thiểu các tác động bất lợi của các thể THA này lên cơ quan đích và sức khỏe chung của người bệnh.

\section{TÀI LIÊU THAM KHẢO}

1. Nguyễn Trần Tuyết Trinh (2014) "Khảo sát tình hình tăng huyết áp ẩn giấu trên bệnh nhân đái tháo đường típ 2". Tạp chi Y hoc Tp.Hồ Chí Minh, 18 (1), tr.430-434

2. Võ Thị Hà Hoa, Đặng Văn Trí (2013) "Khảo sát đặc điểm biến thiên huyết áp ở bệnh nhân tăng huyết áp ẩn giấu qua Holter huyết áp 24 giờ". Tap chi $Y$ hoc Tp.Hồ Chí Minh, 17 (3), tr.218-224

3. Chokshi NP, Grossman E, Messerli FH (2013) "Blood pressure and diabetes: vicious twins". Heart, 99(8), pp.577-585.

4. Gorostidi M, de la Sierra A, GonzálezAlbarrán $\mathrm{O}$, Segura J, de la Cruz JJ, Vinyoles E, Llisterri JL, Aranda P, Ruilope LM, Banegas JR (2011) "Abnormalities in ambulatory blood pressure monitoring in hypertensive patients with diabetes". Hypertens Res, 34 (11), pp.1185-9

5. Hermida RC, Smolensky MH, Ayala DE, Portaluppi F (2015) “Ambulatory Blood 
Pressure Monitoring (ABPM) as the reference standard for diagnosis of hypertension and assessment of vascular risk in adults". Chronobiol Int, 32 (10), pp.1329-1342.

6. Leiria LF, Severo MD, Ledur PS, Becker AD, Aguiar FM, Massierer D, Freitas VC, Schaan BD, Gus M (2015) "White coat effect and masked uncontrolled hypertension in treated hypertensivediabetic patients: Prevalence and target organ damage". Journal of diabetes, 7 (5), pp.699-707.

7. Mancia G, De Backer G, Dominiczak A, et al (2007) "2007 Guidelines for the management of arterial hypertension The Task Force for the Management of Arterial Hypertension of the European Sociaty of Hypertension (ESH) and of the European Society of Cardiology(ESC)".
European Heart Journal, 28, pp.14621536.

8. Mazze RS, Robinson R, Simonson G, Idrogo M, Simpson B, Kendall D, Bergenstal R (2004) "Undetected, uncontrolled blood pressure in type 2 diabetes: self-monitored blood pressure profiles". Blood Press, 13, pp.335-42.

9. Tomiyama $M$, Horio $T$, Yoshii $M$, Takiuchi S, Kamide K, Nakamura S, Yoshihara F, Nakahama H, Inenaga $T$, Kawano Y (2006) "Masked hypertension and target organ damage in treated hypertensive patients". Am J Hypertens, 19 (9), pp.880-6.

10. Yano Y, Bakris GL (2013) "Recognition and management of masked hypertension: a review and novel approach". Journal of the American Society of Hypertension, 7 (3), pp.244-25 